\title{
AUTOMATIC GENERATION OF BIM USING PARAMETRIC FAMILY
}

\author{
*J. Lee, Y. Liu, and J. Kang \\ Texas A\&M University \\ 3137 TAMU \\ Langford Building A, Room 424 \\ College Station, Texas 77843-3137 \\ United States \\ (*Corresponding author: jeffyi@tamu.edu) \\ S. Ahn \\ Samsung C\&T Corporation \\ 1321-20 Seocho 2-Dong, Seocho-Gu, \\ Seoul, 137-857 \\ Republic of Korea
}




\title{
AUTOMATIC GENERATION OF BIM USING PARAMETRIC FAMILY
}

\begin{abstract}
A monolithic caisson is one of the major structural components commonly used in the construction of docks, breakwaters, and container terminal quay walls. Since the structure of monolithic caissons is typical and somewhat simple, its design process is also typical and repetitive, but still time consuming. To reduce the total time and enhance productivity, we developed a parametric model in Revit to automatically generate a 3D model of a monolithic caisson. It is designed to generate the Revit model of a caisson with concrete body and reinforcing bars. The size of caisson, the number of reinforcing bars, and the space between reinforcing bars are automatically changed when users update parameters. This paper presents how we developed this parametric family in Revit for monolithic caisson design and how it would enhance its design process.
\end{abstract}

\section{KEYWORDS}

BIM, Parametric modeling, Revit Family, automatic generation

\section{INTRODUCTION}

Construction projects are usually fragmented into small categories. People in each subgroup tend to communicate with others by using paper-based data like 2-dimensional (2D) shop drawings, structural analysis reports, and specification criteria. If there are errors or missing data, unexpected cost and time may be required. According to the report (Gallaher et al., 2004), $\$ 15.8$ billion in annual interoperability costs were quantified for the facilities industry in 2002 because of inconsistent technology adoption and deficient interoperability between stakeholders. Another issue is the necessary of extra time and cost for estimation, energy usage analysis, and structural analysis. Since these jobs are done at the end of the design process, it can be too late to adequately reflect the change in design. To avoid these time consuming processes, Building Information Modeling (BIM) using parametric modeling is an alternative for producing hundreds of shop drawings. Eastman (2008) describes the advantages of using BIM during the design stage as follows; rapidly and accurately visualizing design, automatically correcting in lower levels for design change, producing accurate and consistent 2D shop drawings at any phases of design, collaborating in early design phase, and so on.

A monolithic caisson, similar to open caissons, is one of the major structural components commonly used in the construction of docks, breakwaters, and container terminal quay walls. Since the structure of monolithic caissons is typical and somewhat simple, its design process is also typical and repetitive. Shop drawings of the reinforcing bars are also typical and repetitive, but it takes time to produce the number of shop drawings required on big projects. It also takes time to develop subsequent tasks such as scheduling bar charts and calculating the material cost. If we can get the process of generating the rebar shop drawings automatically, we should be able to speed up the process of calculating the material cost and even take a look at alternative options within a relatively short amount of time.

BIM applications, which are basically object-oriented parametric 3-dimensional (3D) model authoring tools, caught our attention because of their ability to generate 2D drawings and produce the bill of materials from the 3D model. Many BIM applications also allow users to add additional functions on top of their engine. For instance, Revit, one of the popular BIM authoring tools in North America, allows users 
to develop a parametric family representing a certain structure, in which structural components are connected over parameters.

Even though many new building projects have adopted BIM using the idea of parametric design, it is rarely applied the civil engineering industry. This paper presents how we develop a parametric family in Revit to automatically generate a 3D BIM model of a monolithic caisson as well as how it works to speed up the process of generating shop drawings.

\section{RELATED BACKGROUND RESEARCH}

In the Architecture, Engineering, Construction and Facility Management (AEC/FM) industry, object-oriented parametric modeling not only provides intelligent behavior of objects but also helps to create a huge and complex model as a $3 \mathrm{D}$ object. It is capable of producing simple and repetitive shop drawings. Parametric modeling uses parameters like numbers or characteristics to decide geometric shape and properties, and to define relationships between model components (Autodesk, 2007). For instance, the diameters of re-bars are 1 and 3 inches for type 1 and 2, respectively. This means that during the modeling stages, we capture the design criteria, get the benefits of an easier editing process, and maintain the primary design purpose. As Autodesk (2007) embedded the parametric modeling engine, Revit has been enhanced the uses of 3D digital BIM models such as essence of design, design analysis, documentation, etc.

Some researchers have studied the application of parametric modeling in various areas. Duygu and Yan (2011) explored the capabilities of BIM usage to achieve the variety and flexibility in design extending to the urban scale. Kim et al. (2011) described whether parametric modeling could represent the provisions and constraints of Form-Based Codes (FBC) or not. They assumed that application programming interface (API) for parametric modeling could support the planning of the rules and regulations found in FBCs. Geyer and Buchholz (2012) also proposed parametric modeling as a building and city planning tool. This features closed water cycles, renewable energy production and use, thermochemical energy accumulation and transport of energy for heating and cooling, as well as transformation of biomass into pyrogenic carbon.

On the other hand, other researchers studied the advantages of parametric modeling. Wacks and Barak (2008) already studied the impact of 3D parametric modeling of a building on productivity. They said that $21 \%$ to $61 \%$ of total time was reduced by applying $3 \mathrm{D}$ parametric modeling into the typical structural engineering practice. Parsa (2010) investigated the necessity of temporary works as subcontractors were more interested in using BIM in real projects. He created predefined parametric families for construction phases like formworks and shoring systems and found that they allowed people to speed up the modeling process as well as better understand the 3D models.

\section{OVERVIEW OF PARAMETRIC FAMILY}

In order to create a 3D model of a caisson structure, we utilize a parametric family in this study. A Revit family is an element group which has a set of common properties, called parameters, and relative graphical representation. Parametric components, known as families, are the basic building components of all Revit projects. Revit projects consists of families from structural elements, walls, roofs, windows, and doors. They are used for constructing building models, call-outs, equipment, tags, and detail elements, which are used for documenting the building model. These families can be used to create a variety of furniture by changing family parameters, type parameters, and instance parameters. This is the basic method for changing the geometry of building elements (Autodesk, 2009).

Another advantage of using a family is that programming language or coding is unnecessary to produce a customized family. We just need to create a geometric shape and assign dimensions as parameters, which we want them to make adjustable. If a desk has a height parameter, it is possible to change the height of the desk as much desired.

There are three kinds of families in Revit; system family, in-place family, and loadable family (Autodesk, 2009). In this study, we make use of the loadable family. It is easily created, stored, and edited 
by end users because its application is diverse and broad. Different from a system family, it is able to be saved as an individual 'rfa' file out of Revit's system and opened in Revit projects like library files. Thus, by creating a loadable family, we are able to use it in a variety of projects.

\section{METHODS}

To automatically generate a 3D BIM model of a monolithic caisson, we develop a parametric family in Revit. The procedure for developing a new loadable family is shown in Figure 1. It begins with opening a template which is provided and supported by Revit. The template file includes information about developing a family. For example, the wall template family has property sets specific to walls. The geometric shape of an object family is then designed. After deciding and assigning parameters, we define the type of family. Before loading it into the project, check availability and test the created family. Families, family types, and family parameters have flexibility enough to provide control in every instance within a Revit project. They allow for variation and change in elements, which is the basis of parametric modeling (Autodesk, 2009).

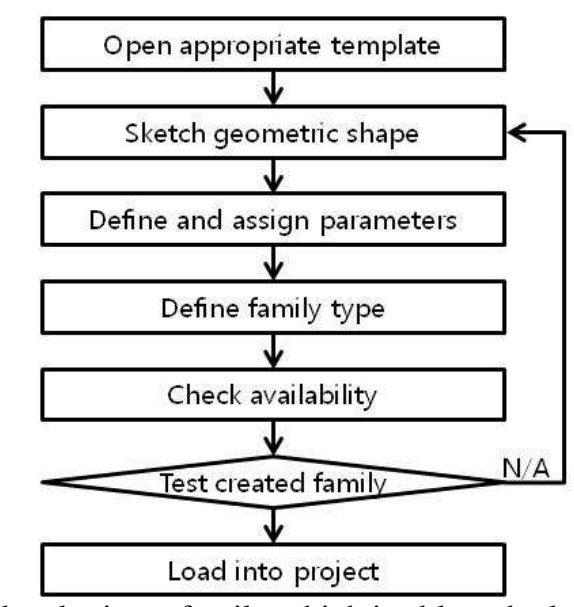

Figure 1 - Procedure of developing a family which is able to be loaded in the project

Through this procedure, we create the family of the caisson concrete body and the reinforcing bars in 3D as shown in Figure 2. Since each wall of a caisson has different openings, we are not able to use the same wall family. Even though the dimensions of the walls are the same, it is not possible to apply the same family on the different geometric shapes. Thus, we create an entire caisson structure in one nested family. The number of walls in both East - West and South - North directions are not changeable. Next, we assign parameters for each dimension. We assign the thickness of each wall as parameters, so that it can be controlled by end users. Additionally, we assign the height of caisson, thickness of foundation concrete, etc. as parameters. These dimensions can be changed by input data. While only dimension information is required to define a caisson concrete body, the number parameters of re-bars in a certain section are required to define how many re-bars are necessary. For instance, using the following equation 1, the number of re-bars required in the horizontal wall is calculated with two parameters: Height of wall and Gap between re-bars. Likewise, the number of re-bars in other sections is calculated. Figure 3 shows an example of re-bars uploaded in the nested family of caisson and Figure 4 shows these number parameters in Revit parameter windows.

$$
(\text { Number of re-bars in vertical wall })=(\text { Height of wall }) /(\text { Gap between re-bars })+1
$$

Finally, we collaborate all these families into the 'Caisson Family' at the appropriate location. It is a nested family which includes other families. We are now ready to use the caisson family for a wide range of applications. In the Revit project we can double check again to confirm that the family is working well 
by changing each parameter one by one. Finally, the size of caisson, the number of reinforcing bars, and the space between reinforcing bars are automatically changed when users update the parameters.

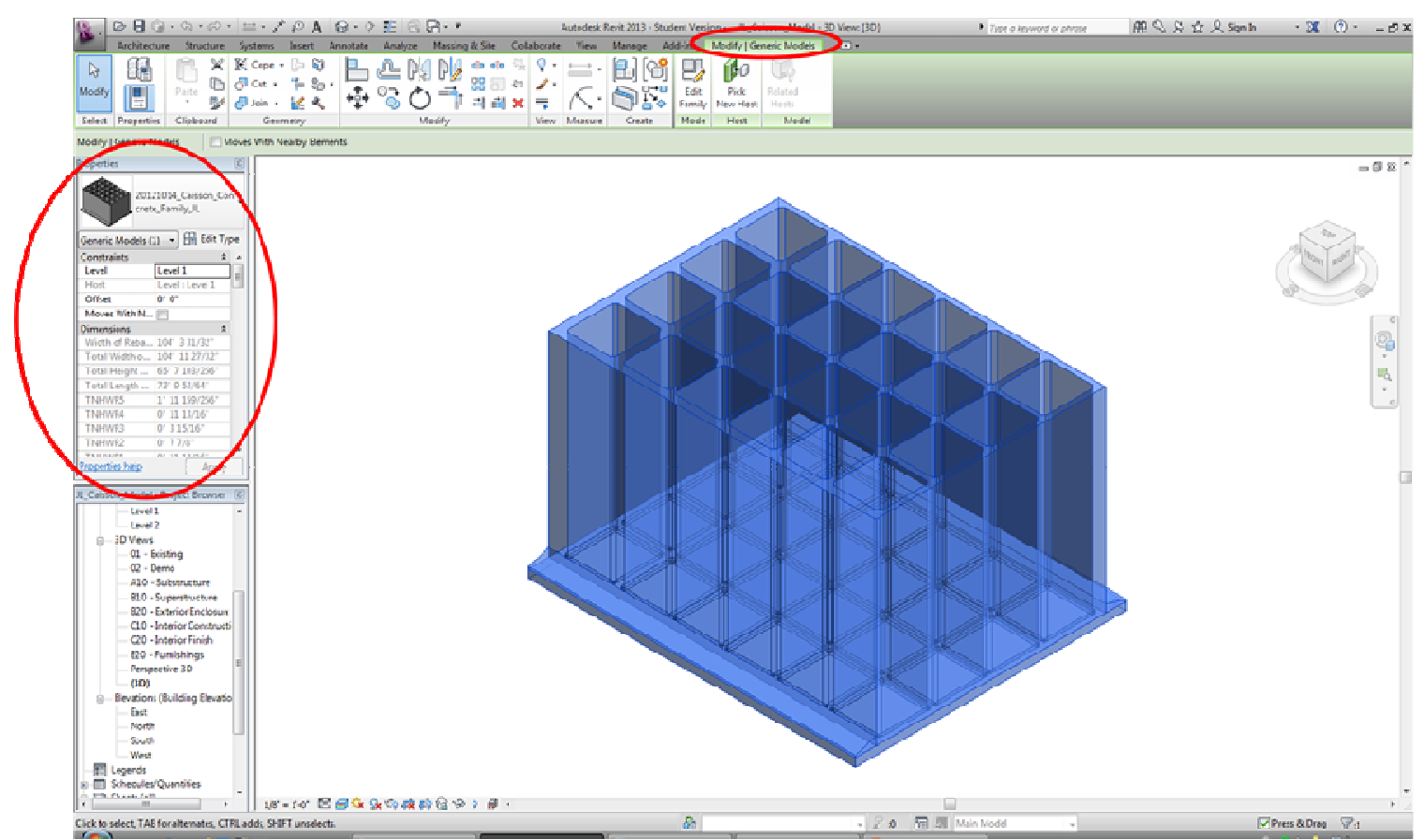

Figure 2 - Overall geometric shape with parameters of the Caisson family in a Revit project

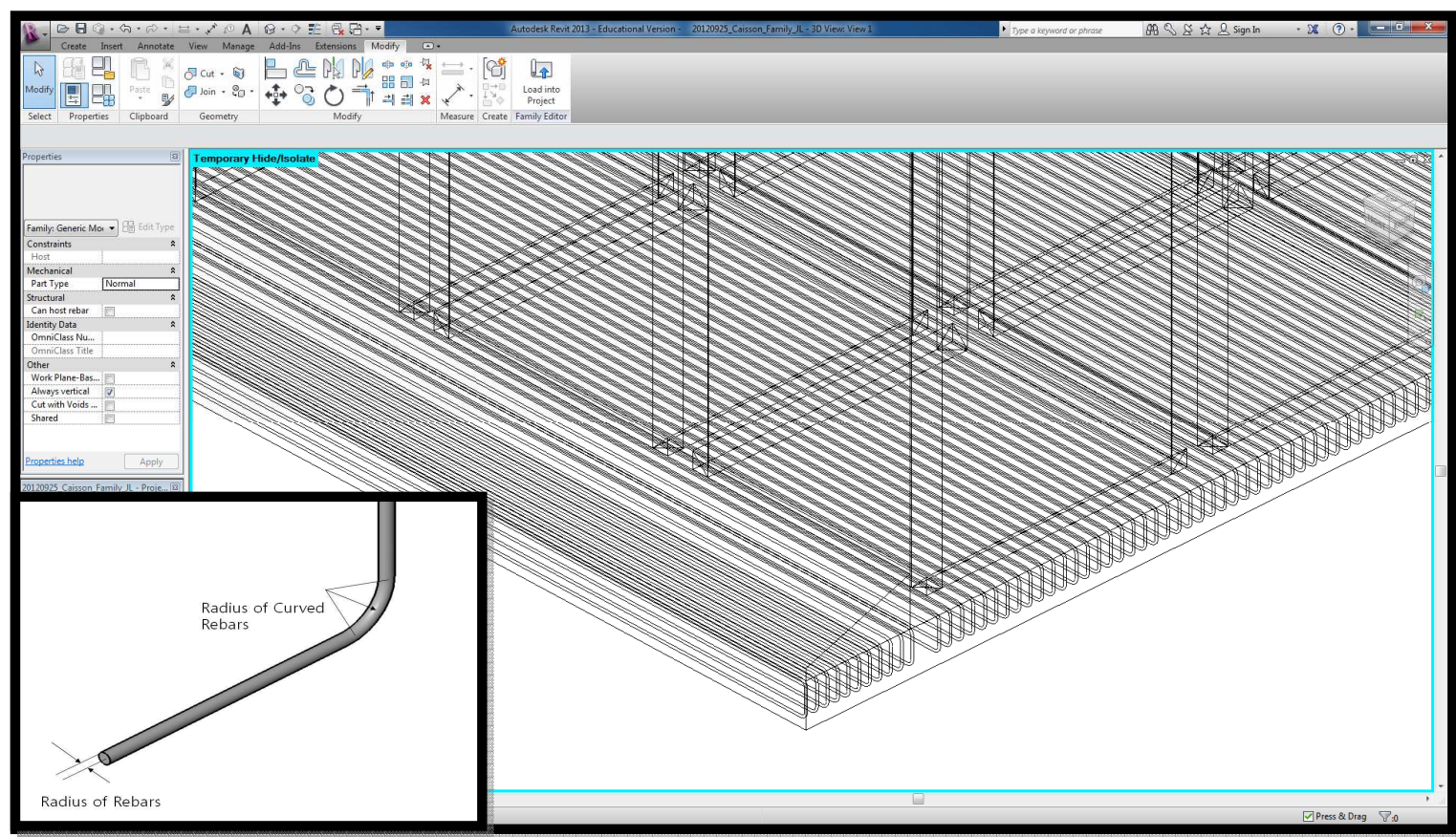

Figure 3 - Example of re-bars applied in the nested family of caisson 


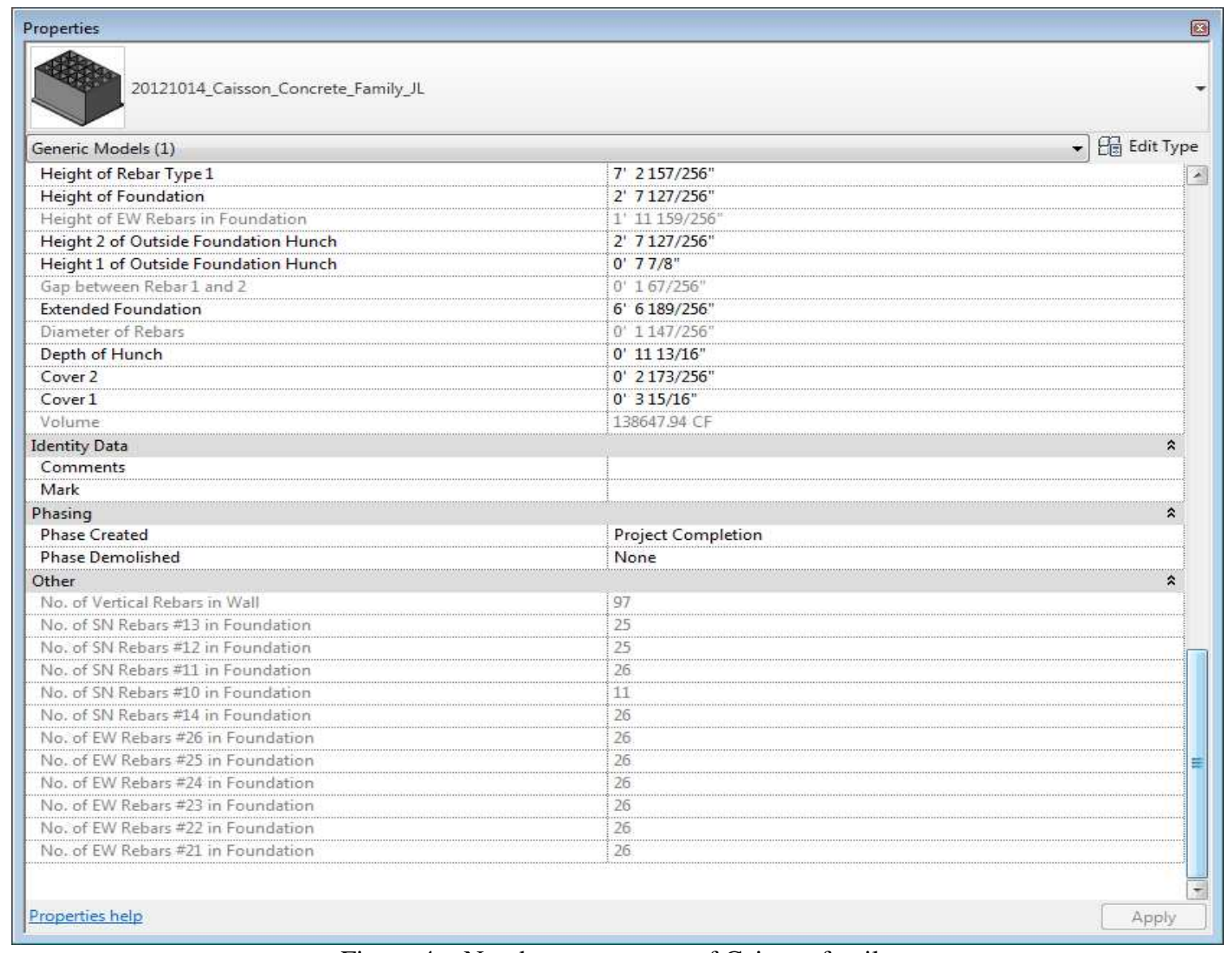

Figure 4 - Number parameters of Caisson family property

\section{DISCUSSION}

In a real project, 51 caissons of three different types were required for a harbor in South Korea. Using the traditional approach, designers were required to produce over one hundred $2 \mathrm{D}$ drawings for every type of caisson. If we assumed that it took an average of 1 hour to produce a $2 \mathrm{D}$ drawing from scratch using a Computer Aided Design (CAD) application, the total amount of time to finish caisson design would have been about 300 hours. However, once we created a caisson family, the time to produce three different types of caisson structures was greatly reduced. It took less than one hour to change the dimensions, 72 hours to create a parametric family and an additional 10 hours to set up the documentation works. Therefore, the total amount of time spent on this project was approximately 83 hours, $27 \%$ of the traditional method. Even though effectiveness does depend on the user's background, proficiency, and mastery of Revit parametric modeling skills and documentation skills, this shows a great reduction in the time required to complete the drawings. We also expect to speed up the process of design, calculation of material cost, and to see an overall increase of productivity.

\section{CONCLUSIONS}

This paper presents the Revit parametric family we developed in an attempt to speed up the process of creating a 3D model of the monolithic caissons that have been frequently used for container terminal construction in South Korea. The structure of monolithic caissons is typical and somewhat simple, its design process is also typical and repetitive. Shop drawings of the reinforcing bars are also typical and 
repetitive, but it takes time to produce a lot of $2 \mathrm{D}$ shop drawings. In this study, we get the process of generating the 2D shop drawings automatically out of 3D model. We parametrically model the 3D caisson family in Revit. This dynamic family contains 6 different types of re-bars as well as concrete body of caisson. We apply it to produce traditional 2D drawings. In the actual project of harbor construction in South Korea, 51 caissons of three different types were required. Designers produced over 100 drawings for each type of caisson. They spent approximately 300 hours in total creating the drawings. Ultimately, we had the same product in as little as $27 \%$ of the time required using traditional methods.

The significance of this study is the potential applicability of parametric modeling to civil infrastructures because of the relatively unsophisticated design required. Civil infrastructure is more straightforward and repetitive than other building structures. However, new parameters like structural safety can be considered according to (1) the specification criteria, (2) the purpose of civil structures, (3) the location of structures, and so on.

\section{REFERENCES}

Autodesk (2007), Parametric Building Modeling: BIM's Foundation, Autodesk, Retrieved at http://images.autodesk.com/apac_india_main/files/gb_revit_bim_parametric_building_modeling j an07.pdf

Autodesk (2009), Revit Architecture (2010), Families guide: Imperial Tutorials, Autodesk, Retrieved at http://usa.autodesk.com/adsk/servlet/item?siteID=123112\&id=13376394

Chuck Eastman, Paul Teicholz, Rafael Sacks, and Kathleen Liston (2008), BIM Handbook: A Guide to Building Information Modeling for Owners, Managers, Designers, Engineers and Contractors, John Wiley \& Sons.

Duygu Yenerim and Wei Yan (2011), "BIM-Based Parametric Modeling: A Case Study", Proceedings of MSV'11 - The 2011 International Conference on Modeling, Simulation and Visualization Methods, Las Vegas, NV.

Jongbum Kim, Mark Clayton, and Wei Yan (2011), "Parametric Form-Based Codes: Incorporation of landuse regulations into Building Information Models", the Proceedings of ACADIA 2011 Regional Conference: Parametricism: Student Performance Criteria (SPC), University of NebraskaLincoln.

Michael Gallaher, Alan O'Connor, John Dettbarn, and Linda Gilday (2004), "Cost Analysis of Inadequate Interoperability in the U.S. Capital Facilities Industry", National Institute of Standards and Technology, Retrieved at http://fire.nist.gov/bfrlpubs/build04/PDF/b04022.pdf

Parsa Sabahi (2010) Speeding up the process of modeling temporary structures in a building information model using predefined families, (Master's dissertation). Texas A\&M University, Texas, US.

Philipp Geyer and Martin Buchholz (2012), "Parametric systems modeling for sustainable energy and resource flows in buildings and their urban environment", Automation in Construction, 22, pp. 7080.

Rafael Sacks and Ronen Barak (2008), "Impact of three-dimensional parametric modeling of buildings on productivity in structural engineering", Automation in Construction, 17, pp. 439-449. 